\title{
Anaphors in Toto
}

\author{
Atanu Saha \\ School of Languages and Linguistics, Jadavpur University \\ Kolkata, India \\ E-mail: atanu.jnu@gmail.com
}

Received: July 7, 2019 Accepted: November 28, 2019 Published: December 2, 2019

doi:10.5296/ijl.v11i6.15034

URL: https://doi.org/10.5296/ijl.v11i6.15034

\begin{abstract}
In this paper, I have discussed the anaphors i.e. reflexives and reciprocals in Toto and argued that the language employs nominal expressions and uses the syntactic strategy known as compositional strategy (like herself and each other in English). In case of reciprocals, there is a lexical counterpart other than the compositional strategy but it is hardly used by the speakers.
\end{abstract}

Keywords: Anaphors, Toto, Tibeto Burman, Endangered language, Nominal strategy

\section{Introduction}

The paper discusses the anaphors i.e. reflexives and reciprocals in Toto, an endangered language of India. My prime argument is that the language employs nominal expressions and uses a syntactic strategy like herself and each other in English. Totos use a nominal self-pronoun for reflexivity. In case of reciprocals, there is a lexical counterpart other than the compositional strategy but it is hardly used by the speakers. Toto belongs to Tibeto Burman family and it is an endangered language spoken in the Alipurduar District of West Bengal in India. The language does not have a written script and currently the speakers are trying to develop a script on their own.

The paper is distributed over the following sections. It begins with a description of the language and the demography in 1.1. Then, I have accrued a couple of research questions followed by a description of the methodology in section 2 . In section 3 , I have discussed the reflexives in Toto and section 4 discusses the reciprocals. The conclusions and a summary of anaphora strategies are noted in section 5.

\subsection{Demography of the Language}

According to (Moseley, 2010), Toto is considered as one of the critically endangered 


\section{Ml Macrothink}

International Journal of Linguistics

ISSN 1948-5425

2019, Vol. 11, No. 6

languages of India. According to (Simons, 2017) there are only 1400 people who speak Toto. The other dominant languages of the regions are Bangla and Nepali. Almost all the Toto speakers can speak Bangla and or Nepali along with Toto.

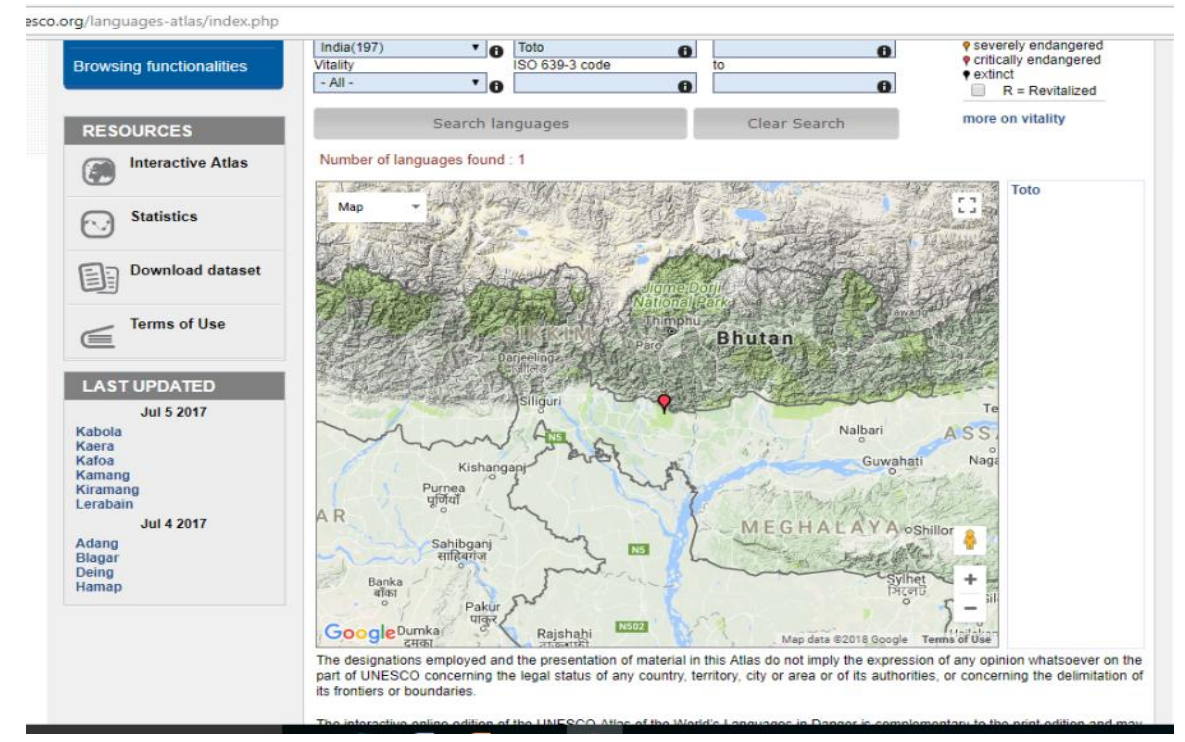

Figure 1. Toto speaking area

In this paper, my objective is to describe the reflexive and reciprocal constructions in Toto. The main research questions are as the following:

1) How are reflexivity and reciprocity expressed in the language? (Geniušien e, 1987) emphasizes on the following aspects of reflexivity e.g. a dedicated reflexive morphology for the language in question, number of morphemes to show reflexivization, relation of the reflexive marker with pronouns, Agreement with respect to the number and gender, Syntactic positioning with respect to the verb, transitive intransitive distinction, lexical or grammatical strategy, binding domain and the effect on valency.

2) How forms and functions of those two types of constructions (reflexivity and reciprocity) are related as classified in (Subbarao, 2012) for the anaphors of South Asian Languages i.e.

(i) A nominal anaphor (reflexive or reciprocal), or

(ii) A verbal anaphor (a verbal clitic for the reflexive or reciprocal), or

(iii) Both nominal and verbal anaphors.

\section{Methodology}

In order to elicit the data, I have used the Berlin - Utrecht Reciprocals questionnaire, survey $\&$ outline edited by (Dimitriadis, 2006). A field survey was conducted in 2016 at Totopara and the data was collected from two speakers and verified from a third Toto Speaker. For glossing the data, I have primarily followed the Leipzig Gloss rules (Conventions for interlinear morpheme-by-morpheme glosses, 2015). 


\section{Reflexives}

Reflexivity in Toto is expressed by the nominal reflexive $\operatorname{tati}_{n} i$ followed by a pair of suffixes ray and -nay shown in the examples (1-2).

1. Janti-ha tati-ray yacpa-din-na (Own data, 2016)

santi-AG self-NS hit- CONT-NFUT.R

'Santi is hitting herself.'

2. Janti-ha tati-nay Jejey -mi

santi-AG self-S like/love- NFUT.IRR

'Santi liked/loved herself.'

The suffixes - ray and -nay show a complementary distinction as the former show up in case of non-stative verbs and the later in case of stative ones. The distributions are shown below:

Table 1. Stative vs. non-stative

\begin{tabular}{ll}
\hline Non Stative verbs & Stative verbs \\
\hline Walk, Eat, Play & See, Like, Love \\
\hline Reflexive + -ray & Reflexive+ -nay \\
\hline
\end{tabular}

\subsection{Body Part/ Wash/ Subject Oriented Reflexives}

In case of other types of reflexives, - ray shows up again in case of subject-oriented reflexives such as in (4-5).

4. ka ka-ray nit $\int \mathrm{p}-$ ro

\section{I-NS wear-FUT}

'You will wear (clothes) by yourself'.

5. ka ka-ray cəp-ro

I I-NS eat-FUT

'I will eat by myself'.

The suffix -nay shows up in case of stative predicates as shown in (6-7) below.

6. Ka ka-hin-nay ıејen-na

\section{I-ACC-S like-NFUT.R}

'I like myself.'

7. Kabi kabi-hin-nay Jejen-su-na

We we-ACC-S like-PL-NFUT.R

'We like ourselves'. 


\section{Macrothink}

Wash verbs also show reflexivity as shown in (8).

8. ka ka-ray ti up-ro

I I-NS water bath-FUT

'I will bath myself (with water).

\subsection{Long Distance Binding}

Toto reflexives show long-distance binding as shown in example (9).

\begin{tabular}{|c|c|c|c|c|}
\hline 9. Јюn & Jay-mi & aku-ha tati-nay & 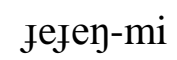 & (Wide scope) \\
\hline Joh & say-IRR.NFUT & he-AG & self-S & like-NFUT.IRR \\
\hline
\end{tabular}

' $J_{o h n}$ said that he likes himself $_{\mathrm{i} / \mathrm{j}}$ '.

In (9), the reflexive pronoun tati-nay refers to either the local antecedent he or the long-distance matrix subject John.

10. „on Jay-mi aku-ha aku-hin-nay Jejey-mi (Narrow scope)

John say-IRR.NFUT he-AG he-ACC-S like-NFUT.IRR

' $\mathrm{John}_{\mathrm{i}}$ said that he likes himself $_{\mathrm{j}}$ '.

In (10), on the other hand, the reflexive pronoun aku-hin-nay can only refer to the local subject he and it cannot refer back to the long-distance antecedent. We now turn to the reciprocal constructions in the language in the following section.

\section{Reciprocals}

The reciprocal construction shows a nominal strategy as in (12).

12. ebiha ebe ebe-ta ga-din-na

they one one-LOC sit-CONT-NFUT.R

'They are sitting one after another'.

However, a regional variation can be noticed as in one of the Toto speakers used ebe ebe and the other used eco eco for each other.

13. ebiha eco eco-hin ЈeJen-na

they one one-ACC like-NFUT.R

'They like each other'.

Another morphological variant can also be noticed in the following examples:

14. i deabi taibilərai-hin tæ-din-na

these people each other-ACC touch-CONT-NFUT.R 
'They are touching each other.'

15. i deabi taibilorai-ko (Note 1) wæ-tay-na

these people each other-ACC hug-CONT-NFUT.R

'They are hugging each other'.

In the above examples instead of a combinatory nominal reciprocal, a lexical reciprocal taibilarai is used.

In Toto, when a pluractional suffix shows up in a reciprocal construction, it shows the multiplicity of events as shown in (16). The predicate yields a distributive reading.

16. tutfo deabi taibilərai-hin wæ-tan-su-na

six people each other-ACC hug-CONT-PL-NFUT.R

'six people are hugging each other.'

4.1 Ambiguity in LDB ReciprocalsToto reciprocals also allow the long-distance binding of the reciprocal constructions as shown in (17).

17. Jon so meri no-mi u-bi-ha eco eco nt-din-na

john and Mary think- NFUT.IRR they-AG one one fight-CONT-NFUT.R

'John and Mary $\mathrm{i}_{\mathrm{i} j \mathrm{j}}$ think that they $\mathrm{y}_{\mathrm{i} / \mathrm{j}}$ are fighting with each other $\mathrm{i}_{\mathrm{i} j \mathrm{j}}$.'

In (17), there are two possible readings. On one reading the fight can take place between some people but not John and Mary and in that sense, it is a narrow scope reading while the second possibility is that the fighting can take place only between John and Mary.

\section{Conclusion}

The facts I have inferred from Toto and raised in terms of the research questions in 1)-2) are summarized as below:

Table 1. Morpho syntactic properties of Anaphors

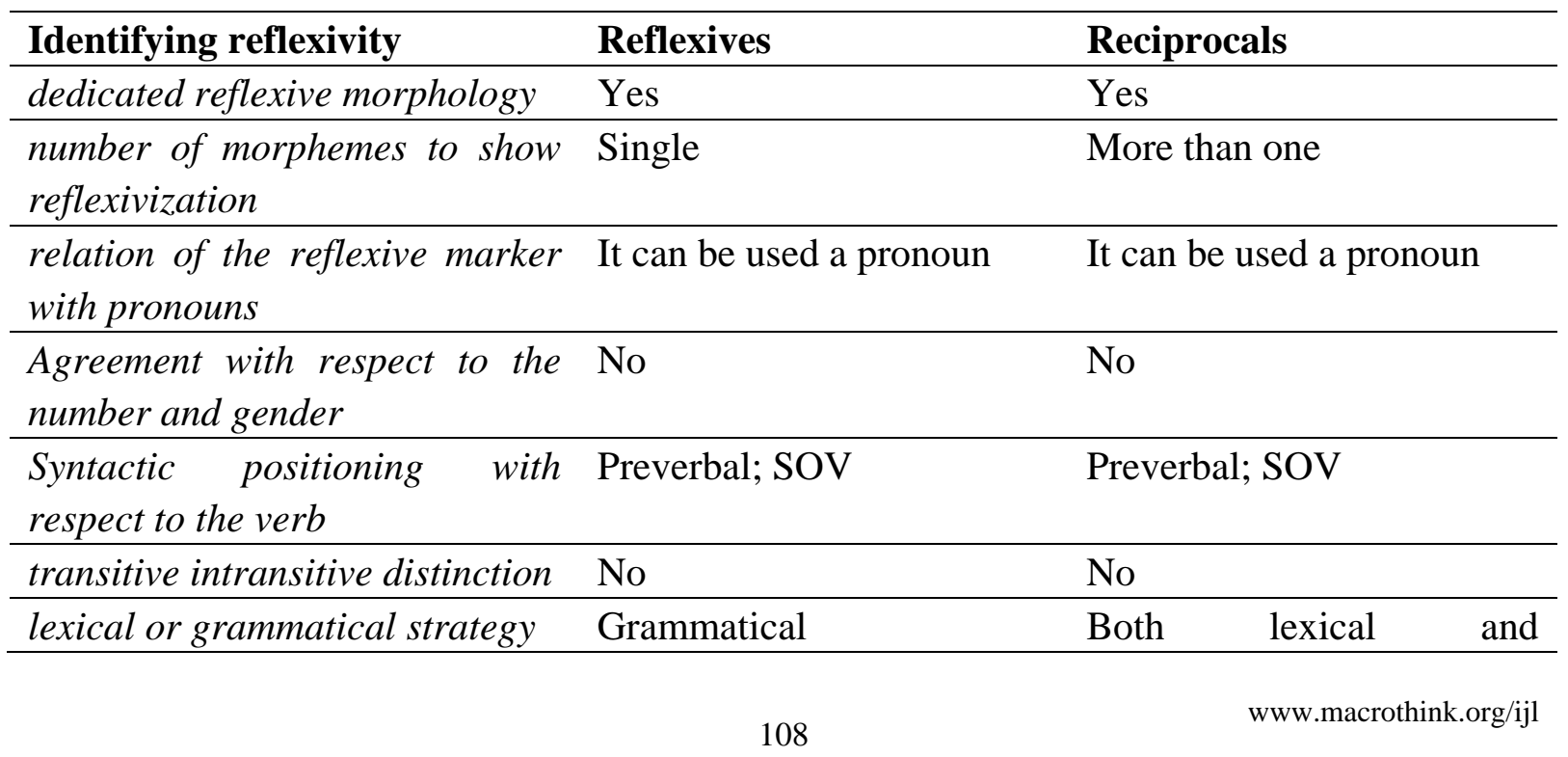




\begin{tabular}{lll}
\hline & & grammatical \\
\hline the binding domain & Both local and non-local & Both local and non-local \\
\hline the effect on the valency & No change & No change \\
\hline Form function & \\
\hline i)A nominal anaphor (reflexive & Only Nominal & Only nominal \\
or reciprocal), or & \\
ii)A verbal anaphor (a verbal & \\
clitic for the reflexive or & \\
reciprocal), or (iii) Both & \\
nominal and verbal anaphors & \\
\hline
\end{tabular}

I argue that Toto uses a nominal strategy for both reflexives and reciprocals. The reflexive marker - $t_{n} a t i$ shows up with two different suffixes -nay \& -ray to mark the distinction between stative and non-stative events. In reciprocal constructions, both compositional (eco eco, ebe ebe) and lexical strategies (taibilarai) are used. Both the reflexives and the reciprocals in Toto show long-distance binding.

As a consequence of language contact, Toto has shifted to compositional strategy which is found in both Bangla and Nepali in the region. The lexical reciprocal marker taibilarai has become a frozen expression in the language and the use of the compositional reciprocal marker is more frequent.

\section{Acknowledgement}

I am indebted to Santi Toto \& Bhabesh Toto of Totopara village for giving me data and their valuable insights and I am also thankful to Sanchita Toto for giving me ample time to crosscheck the data.

List of abbreviations

ACC Accusative

AG Agentive

CONT Continuous

FUT Future

IRR Irrealis

LOC Locative

NFUT Non Future

NS Nonstative

PL Pluractional

R Realis

S Stative 


\section{Macrothink}

International Journal of Linguistics

ISSN 1948-5425 2019, Vol. 11, No. 6

\section{References}

Conventions for interlinear morpheme-by-morpheme glosses. (n.d.). Max Planck Institute Department of Linguistics. Retrieved from https://www.eva.mpg.de/lingua/resources/glossing-rules.php

Dimitriadis, A. (2006). Berlin - Utrecht Reciprocals questionnaire, survey \& outline. Utrecht .

Geniušien`e, E. (1987). The Typology of Reflexives. Berlin: Mouton de Gruyter.

Moseley, C. (2010). Atlas of the World's Languages in Danger. UNESCO Publishing. Retrieved 2017, from http://www.unesco.org/culture/en/endangeredlanguages/atlas

Simons, G. F. (2017). Toto. Ethnologue: Languages of the World. Retrieved from https://www.ethnologue.com/language/txo/18

Subbarao, K. (2012). South Asian Languages: A syntactic typology. CUP.

\section{Note}

Note 1. -ko is the accusative case marker in Nepali, in this case the case marker has been borrowed in Toto.

\section{Copyrights}

Copyright for this article is retained by the author(s), with first publication rights granted to the journal.

This is an open-access article distributed under the terms and conditions of the Creative Commons Attribution license (http://creativecommons.org/licenses/by/4.0/) 